CENTRE FOR EMEA BANKING, FINANCE \& ECONOMICS

An Analysis of Oil Production by OPEC Countries:

Persistence, Breaks and Outliers

Working Paper Series

No 06/11 


\title{
An Analysis of Oil Production by OPEC Countries: Persistence, Breaks, and Outliers
}

\author{
Carlos Pestana Barros ${ }^{1}$, Luis A. Gil-Alana ${ }^{2}$ and James E. Payne ${ }^{3 *}$
}

\begin{abstract}
This study examines the time series behaviour of oil production for OPEC member countries within a fractional integration modelling framework recognizing the potential for structural breaks and outliers. The analysis is undertaken using monthly data from January 1973 to October 2008 for 13 OPEC member countries. The results indicate there is mean reverting persistence in oil production with breaks identified in 10 out of the 13 countries examined. Thus, shocks affecting the structure of OPEC oil production will have persistent effects in the long run for all countries, and in some cases the effects are expected to be permanent.
\end{abstract}

Keywords: Oil production, OPEC, fractional integration, persistence; breaks and outliers.

\footnotetext{
${ }^{1}$ Instituto Superior de Economia e Gestão and Research Unit on Complexity and Economics Technical University of Lisbon Lisbon, Portugal Email: cbarros@iseg.utl.pt

${ }^{2}$ University of Navarra Pamplona, Spain Email: alana@unav.es

${ }^{3}$ Interim Dean and Professor of Economics Department of Economics Illinois State University Normal, IL, 61790-4200 USA Email: jepayne@ilstu.edu
} 


\section{Introduction}

According to the Energy Information Administration, in 2008 roughly $43 \%$ of the world's oil production was attributed OPEC member countries. Furthermore, OPEC member countries have approximately $70 \%$ of the proven oil reserves in the world. Table 1 displays country specific oil production for 1973 and 2008, as one can see oil production in Algeria, Angola, Ecuador, Iraq, Qatar, Saudi Arabia, and the United Arab Emirates (UAE) show an increase while Indonesia, Iran, Kuwait, Libya, Nigeria, and Venezuela show a decrease relative to 1973. Furthermore, the International Energy Agency (IEA) and the Energy Information Administration (EIA) project an increase in global demand for oil over the next several decades which raises the question on whether this increased demand can be met by OPEC oil production.

OPEC's oil production is influenced by a myriad of factors such as the price of oil and market conditions, i.e. the global demand for oil along with the production associated with non-OPEC oil producers and the geopolitical environment. OPEC has generally been successful in utilizing production cuts to prevent declines in price while on the other hand offsetting disruptions in the supply of oil and the rise in oil prices by increasing production. However, the pursuit of output policies has become more complicated given the emergence of the futures market in signaling oil prices and the corresponding adjustments in oil production. Indeed, the effectiveness of output policies hinges on the effectiveness of OPEC to influence market participants' expectations in the futures market along with OPEC's long-term investment plans to expand production capacity (Fattouh, 2007).

By the early 1970s, in addition to the oil embargo, OPEC oil production was influenced by the change in the oil pricing system from multinational oil companies to OPEC with the halt on authorizing new concessions by OPEC governments, movement towards equity participation in the existing concessions, and in some cases the nationalization of the oil industry. As a result by the late 1970s, multinational companies diversified their oil supply sources in the development of oil reserves outside of OPEC. In response to higher oil prices by the early 1980s, the discovery of oil 
reserves in non-OPEC countries in conjunction with advances in new technology brought forth an increase in the supply of oil to the international market resulting in downward pressure on oil prices with OPEC losing market share. With the infusion of non-OPEC oil producers and their prices more responsive to competitive market conditions, OPEC abandoned the administered oil pricing system by the mid-1980s instead moving to market-reference pricing based on the price quotes provided by oil price reporting agencies. However, the limited liquidity of the spot market gave way to the use of the futures market which provided greater liquidity and price transparency.

OPEC would adjust production quotas to achieve a desired price target zone. However, OPEC's ability to influence price is dependent on market participants' expectations in the futures market. Essentially, OPEC's decisions on production quotas provided signals to the market about OPEC's desired range of prices, the effectiveness of the signals depended on the whether the market believed that OPEC could make the necessary production adjustments in light of market conditions (Fattouh, 2007). In the face of a decrease in the global demand for oil, OPEC would attempt to defend a target price by cutting production. However, the success of such production cuts hinges on the coordination efforts and bargaining power of OPEC member countries. On the other hand, while coordination to increase production quotas may be easier with an increase in the global demand for oil, OPEC may not respond quickly to this upward trend given uncertainty about future demand (Fattouh, 2007). Due to the large investment outlays required and the irreversibility of the investment, the decision to wait and not increase oil production would be more profitable than to increase oil production when the trend may turn out to be false (Dixit and Pindyck, 1994; Gately, 2004; Fattouh, 2007).

The ability of OPEC to increase production capacity is also influenced by state control of the oil sector and the geopolitical climate. With respect to investment and production in member countries with state control of the oil sector, the increasing demands on the government to finance other socio-economic projects imposes budgetary constraints on national oil companies to expand production capacity. Also, an unfavorable geopolitical climate for OPEC member countries in terms 
of security concerns and sanctions would have an adverse impact on the investment climate and thus may limit capacity expansion.

In light of the myriad of influences on OPEC's oil production, understanding the time series behavior of OPEC oil production is critical in the assessment of the impact of oil shocks and structural breaks on both oil supply and the repercussions for global economic activity. ${ }^{1}$ Specifically, this study examines the degree of persistence, potential breaks and outliers of oil production for each OPEC member country within a fractional integration modelling framework. In particular, two important features commonly observed in oil production data are the persistence across time (Lien and Root, 1999; Kang et al. 2009) and breaks in production (Altinay and Karagol, 2004; Lee and Chang, 2005; Narayan and Smyth, 2008; Rao and Rao, 2009). ${ }^{2}$ Modelling the degree of persistence is important in that it can reflect the stability of production in a particular country and given the importance of oil production to other sectors of an economy the persistence of such shocks may be transmitted to other sectors of the economy and macroeconomic aggregates as well. Such transmission of shocks has implications for the effectiveness of government intervention or stabilization policies.

Table 1: OPEC Countries Oil Production

\begin{tabular}{|c|c|c|c|c|}
\hline Countries & $\begin{array}{c}\text { Oil prod. in } \\
\text { barrels October } \\
\text { in 2008 }\end{array}$ & $\begin{array}{c}\text { Oil production } \\
\text { in barrels } \\
\text { October in } \\
2008\end{array}$ & $\begin{array}{c}\text { Oil barrel } \\
\text { volatility in the } \\
\text { period } \\
1973-2008\end{array}$ & $\begin{array}{c}\text { Oil Reserves declared } \\
\mathrm{mb} \\
2008\end{array}$ \\
\hline Algeria & 1873.99 & 1059 & 262.407 & 12,200 \\
\hline Angola & 1991 & 162 & 449.489 & 9,500 \\
\hline Ecuador & 496.874 & 220 & 115.679 & 6,511 \\
\hline Indonesia & 990 & 1447 & 192.817 & 3,990 \\
\hline Iran & 4100 & 5977 & 1237.671 & 137,620 \\
\hline Iraq & 2327.578 & 1846 & 890.839 & 115,000 \\
\hline Kuwait & 2628.738 & 3060 & 647.694 & 101,500 \\
\hline Libya & 1745 & 2370 & 342.625 & 44,271 \\
\hline
\end{tabular}




\begin{tabular}{|c|c|c|c|c|}
\hline Nigeria & 2185 & 2200 & 379.696 & 37,200 \\
\hline Qatar & 924.756 & 600 & 182.545 & 25,405 \\
\hline Saudi Arabia & 9400 & 7796 & 1786.932 & 264,063 \\
\hline U. A. E. & 2660.912 & 1669 & 463.972 & 97,800 \\
\hline Venezuela & 2360 & 3381 & 489.067 & 172,323 \\
\hline Total & 33683.85 & 31787 & 4921.017 & $\mathbf{1 , 0 2 7 , 3 8 3}$ \\
\hline
\end{tabular}

Source: Oil production from OPEC Annual Statistics Bulletin 2008 in thousands of barrels per day. Oil reserves in millions of barrels $(\mathrm{mb})$.

Delete the volatility column.

Breaks and outliers are other important features that are present in monthly oil production data which may be attributed to fluctuations in oil prices, changes in the world geopolitical climate, and country-specific socio-economic events, among others. ${ }^{3}$ Indeed, if oil production is stationary I(0), shocks to oil production will be transitory and following major structural breaks in oil production, the supply of oil will return to its original equilibrium with the disruptions in oil production only having a temporary impact on economic activity. However, if oil production contains a unit root (i.e., if it is nonstationary I(1)), shocks to oil production will have persistent effects on the supply of oil with the disruptions in oil production having a permanent impact on economic activity (Narayan et al. 2008). ${ }^{4}$ In the present paper we extend the models based on I(0) and I(1) hypotheses to the fractional I(d) case which permits the examination of the dependence oil production between periods.

Despite the importance of oil as an energy source and the previous research on the oil industry, there are no studies that specifically analyse the persistence, breaks, and outliers associated with OPEC oil production. While studies consider, for example, oil consumption (Mohn and Osmundsen, 2008; Lean and Smyth, 2009), returns on investment in oil (Boone, 2001) and oil exhaustion (Tsoskounoglou et al. 2008; Höök and Aleklett, 2008; Karbassi et al. 2007), no studies have explored the long memory/persistence properties of OPEC oil production.

The remainder of this study is organised as follows. Section 2 presents a review of the previous literature. Section 3 details the methodology. Section 4 presents the data and the 
empirical results. Section 5 deals with the discussion of the results, while Section 6 provides concluding remarks.

\section{Brief Overview of the Literature}

As mentioned earlier, determining whether shocks to oil production are transitory or persistent is relevant in the formulation of energy-related policy as well as government stabilization policies. Though there have been a number of studies investigating the presence of a unit root in energy consumption (Chen and Lee, 2007; Narayan and Smyth, 2007; Hsu et al, 2008; Mishra et al, 2009; Lean and Smyth, 2009; Rao and Rao, 2009), only a few studies examine oil production. ${ }^{5}$

In the process of examining the economic, geological, and institutional determinants of oil production in the lower 48 U.S. states, Kaufmann and Cleveland (2001) use the Augmented Dickey Fuller (ADF, Dickey and Fuller, 1979) unit root test with respect to oil production over the period 1938 to 1991 . Their results fail to reject the null hypothesis of a unit root. Iledare and Olatubi (2006) investigate oil production in the Gulf of Mexico's Outer Continental Shelf using quarterly data from 1948 to 2000 for shallow water and from 1979 to 2000 for deep water, respectively. In both cases, the results of the ADF tests fail to reject the null hypothesis of a unit root. ${ }^{6}$

Narayan et al. (2008) explore the unit root properties of crude oil and NGL production for 60 countries using annual data from 1971 to 2003 . Their analysis begins with the panel unit root tests by Maddala and Wu (1999), Breitung (2000), Levin et al (2002), Im et al (2003), and the panel stationarity test by Hadri (2000) each undertaken without allowance for a structural break. The results for the panel data sets without allowance for a structural break for the entire 60 country panel and the regional panels (OECD, Latin America, Central and Eastern Europe, Africa, Middle East, and Asia) provide mixed evidence of stationarity for crude oil and NGL production. However, further investigation using the panel LM unit root test by Im et al. (2005) with allowance for a structural break reveals that for the entire 60 country panel and five of the six regional panels (OECD, Latin America, Africa, Middle East, and Asia), the null hypothesis of a unit root in crude oil and NGL 
production is rejected at the $1 \%$ significance level while for the Central and Eastern Europe panel, the null hypothesis is rejected at the $10 \%$ level.

Maslyuk and Smyth (2009) apply the threshold unit root tests by Caner and Hansen (2001) using monthly data from January 1973 to December 2007 for crude oil production of 17 countries that include both OPEC and non-OPEC countries. Maslyuk and Smyth (2009) find the presence of threshold effects (i.e. non-linearities) in crude oil production over two regimes. Next, Maslyuk and Smyth (2009) test for a unit root against a non-linear stationary process in two regimes and a partial unit root process when the unit root is present in only one regime. Their results indicate that for 11 countries there is a unit root in both regimes (Indonesia, Kuwait, Nigeria, Qatar, Saudi Arabia, Venezuela, Canada, Norway, USSR/Russia, the UK, and the US); for two countries (China and Egypt) there is a partial unit root in the first regime; and for four countries (Iran, Iraq, Libya, and Mexico) there is a partial unit root in the second regime.

As the previous research indicates, the examination of the long memory (fractional integration) properties of OPEC oil production with the inclusion of structural breaks and outliers has not been explored in the literature.

\section{Methodology}

One characteristic of many economic and financial time series is its nonstationary nature. There exists a variety of models to describe such nonstationarity. Until the 1980s a standard approach was to impose a deterministic (linear or quadratic) function of time, thus assuming that the residuals from the regression model were stationary $I(0)$. Later on, and especially after the seminal work of Nelson and Plosser (1982), there was a general agreement that the nonstationary component of most series was stochastic, and unit roots (or first differences, I(1)) were commonly adopted. However, the I(1) case is merely one particular model to describe such behaviour. In fact, the number of differences required to get $I(0)$ may not necessarily be an integer value but any point in the real line. In such a case, the process is said to be fractionally integrated or $I(d)$. The $I(d)$ 
models belong to a wider class of processes called long memory. We can define long memory in the time domain or in the frequency domain.

Let us consider a zero-mean covariance stationary process $\left\{x_{t}, t=0, \pm 1, \ldots\right\}$ with autocovariance function $\gamma_{u}=E\left(x_{t} x_{t+u}\right)$. The time domain definition of long memory states that $\sum_{u=-\infty}^{\infty}\left|\gamma_{u}\right|=\infty$. Now, assuming that $\mathrm{x}_{\mathrm{t}}$ has an absolutely continuous spectral distribution, so that it has spectral density function

$$
f(\lambda)=\frac{1}{2 \pi}\left(\gamma_{0}+2 \sum_{u=1}^{\infty} \gamma_{u} \cos (\lambda u)\right)
$$

the frequency domain definition of long memory states that the spectral density function is unbounded at some frequency in the interval $[0, \pi)$. Most of the empirical literature has concentrated on the case where the singularity or pole in the spectrum takes place at the 0frequency. This is the standard case of $I(d)$ models of the form:

$$
(1-L)^{d} x_{t}=u_{t}, \quad t=0, \pm 1, \ldots
$$

where $L$ is the lag-operator $\left(L x_{t}=x_{t-1}\right)$ and $u_{t}$ is $I(0)$. Note that the polynomial $(1-\mathrm{L})^{\mathrm{d}}$ in $(2)$ can be expressed in terms of its Binomial expansion, such that, for all real $d$,

$$
(1-L)^{d}=\sum_{j=0}^{\infty} \psi_{j} L^{j}=\sum_{j=0}^{\infty}\left(\begin{array}{l}
d \\
j
\end{array}\right)(-1)^{j} L^{j}=1-d L+\frac{d(d-1)}{2} L^{2}-\ldots
$$

and thus

$$
(1-L)^{d} x_{t}=x_{t}-d x_{t-1}+\frac{d(d-1)}{2} x_{t-2}-\ldots .
$$

In this context, d plays a crucial role since it will be an indicator of the degree of dependence of the time series. Thus, the higher the value of $d$ is, the higher the level of association will be between the observations. On the other hand, the above process also admits an infinite moving average representation such that 


$$
x_{t}=\sum_{k=0}^{\infty} a_{k} u_{t-k},
$$

where

$$
a_{k}=\frac{\Gamma(k+d)}{\Gamma(k+1) \Gamma(d)} .
$$

Thus, the impulse responses are also clearly affected by the magnitude of $d$, and the higher the value of $d$ is, the higher the responses will be. In this context, if $d$ is smaller than 1 , the series will be mean reverting, with shocks having temporary effects, and disappearing in the long run. On the other hand, if $d \geq 1$, shock will be permanent lasting forever unless strong policy measures are adopted. Processes with $d>0$ in (2) display the property of "long memory", characterized because the spectral density function of the process is unbounded at the origin. However, fractional integration may also occur at some other frequencies away from 0 , as in the case of seasonal/cyclical models.

In this study, we estimate d using a Whittle function in the frequency domain (Dahlhaus, 1989) along with a testing procedure developed by Robinson (1994) that permits us to test the null hypothesis $H_{0}$ : $d=d_{0}$ in (2) for any real value $d_{0}$, where $x_{t}$ in (2) can be the errors in a regression model of form:

$$
y_{t}=\beta^{T} z_{t}+x_{t}, \quad t=1,2, \ldots,
$$

where $y_{t}$ is the time series we observe; $\beta$ is a $(k \times 1)$ vector of unknown coefficients; and $z_{t}$ is a set of deterministic terms that might include an intercept (i.e., $z_{t}=1$ ), an intercept with a linear time trend $\left(z_{t}=(1, t)^{\top}\right)$, or any other type of deterministic processes like dummy variables to examine the potential presence of outliers/breaks. This method is briefly described in Appendix 1.

We also examine in the paper the possibility of structural breaks, which are endogenously determined by the model. For simplicity, we describe here the case of a single break and consider a model of the form:

$$
y_{t}=\beta_{1}{ }^{T} z_{t}+x_{t} ; \quad(1-L)^{d_{1}} x_{t}=u_{t}, \quad t=1, \ldots, T_{b} \text {, }
$$

and 


$$
y_{t}=\beta_{2}{ }^{T} z_{t}+x_{t} ; \quad(1-L)^{d_{2}} x_{t}=u_{t}, \quad t=T_{b}+1, \ldots, T,
$$

where the $\beta$ 's are the coefficients corresponding to the deterministic terms; $d_{1}$ and $d_{2}$ may be real values; $u_{t}$ is $I(0)$; and $T_{b}$ is the time of a break that is supposed to be unknown. Note that given the difficulties in distinguishing between models with fractional orders of integration and those with broken deterministic trends (i.e., Diebold and Inoue, 2001; Granger and Hyung, 2004) the issue is relevant. We implement a recent procedure developed by Gil-Alana (2008, see Appendix 2) that is based on minimizing the residuals sum squares in the two subsamples and that can be easily extended to the case of two or more breaks.

\section{Data and Results}

Monthly (seasonally adjusted) data of the oil production of OPEC countries were obtained from January 1973 to October 2008 from the Energy Information Administration web site. The total number of observations is $\mathbf{4 3 1}$ for each country: Algeria, Angola, Ecuador, Indonesia, Iran, Iraq, Kuwait, Libya, Nigeria, Qatar, Saudi Arabia, United Arab Emirates, and Venezuela. Figure 1 displays the time series plots for each OPEC country, measured in thousands of barrel per day. We observe in all cases a strong persistent pattern that is changing across time, suggesting the adoption of fractional integration with and without breaks. 
Figure 1: Time Series Plots

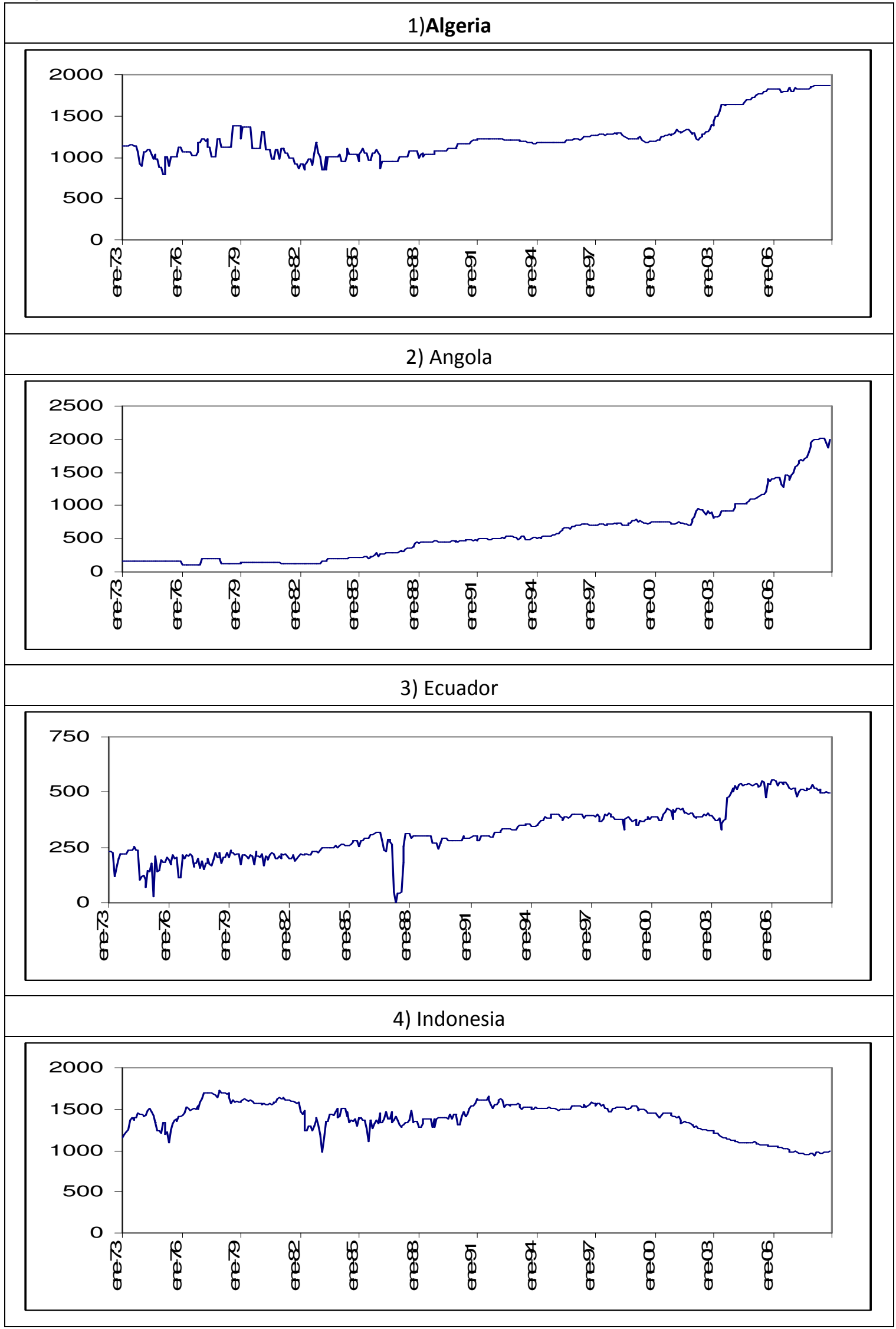




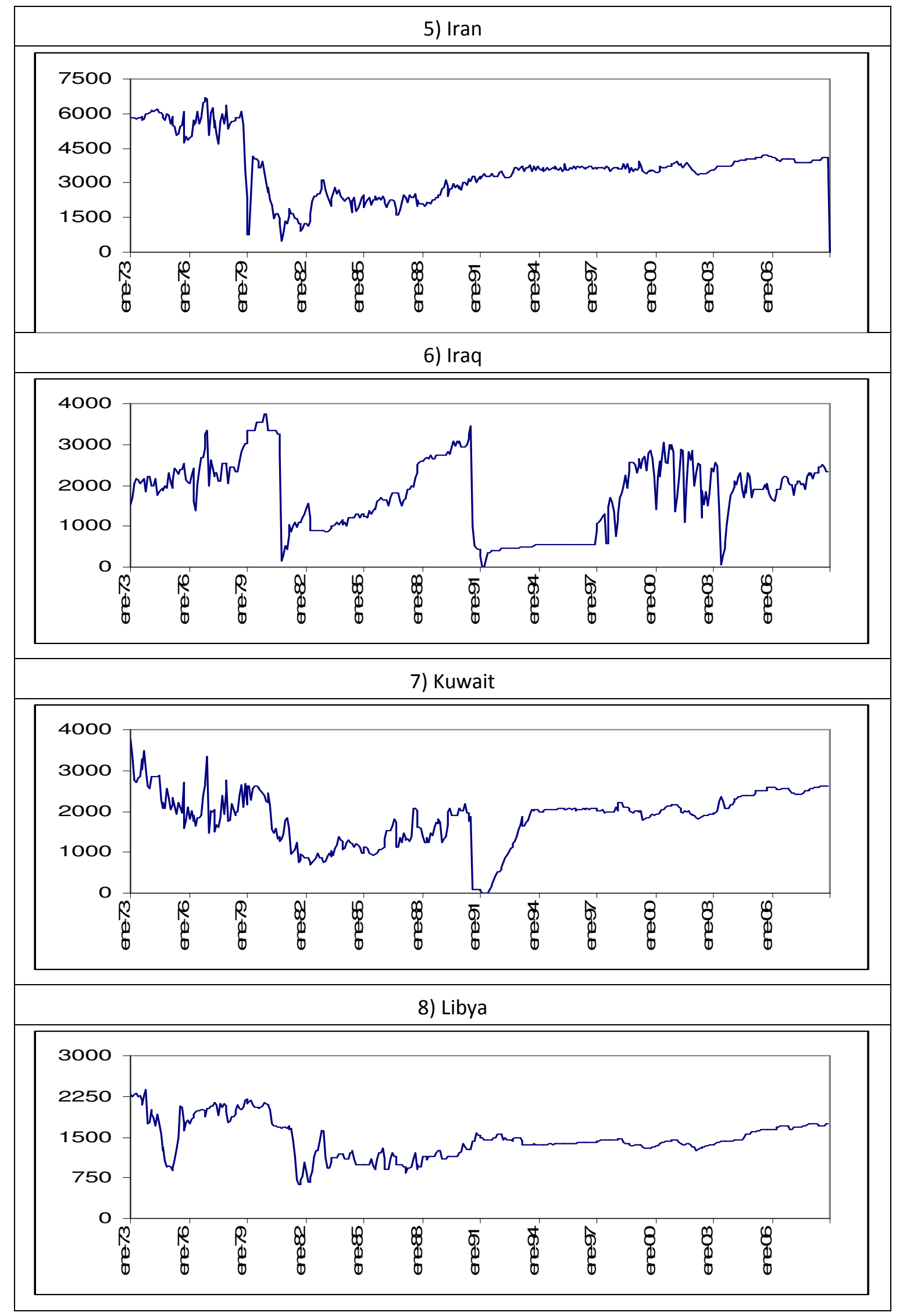




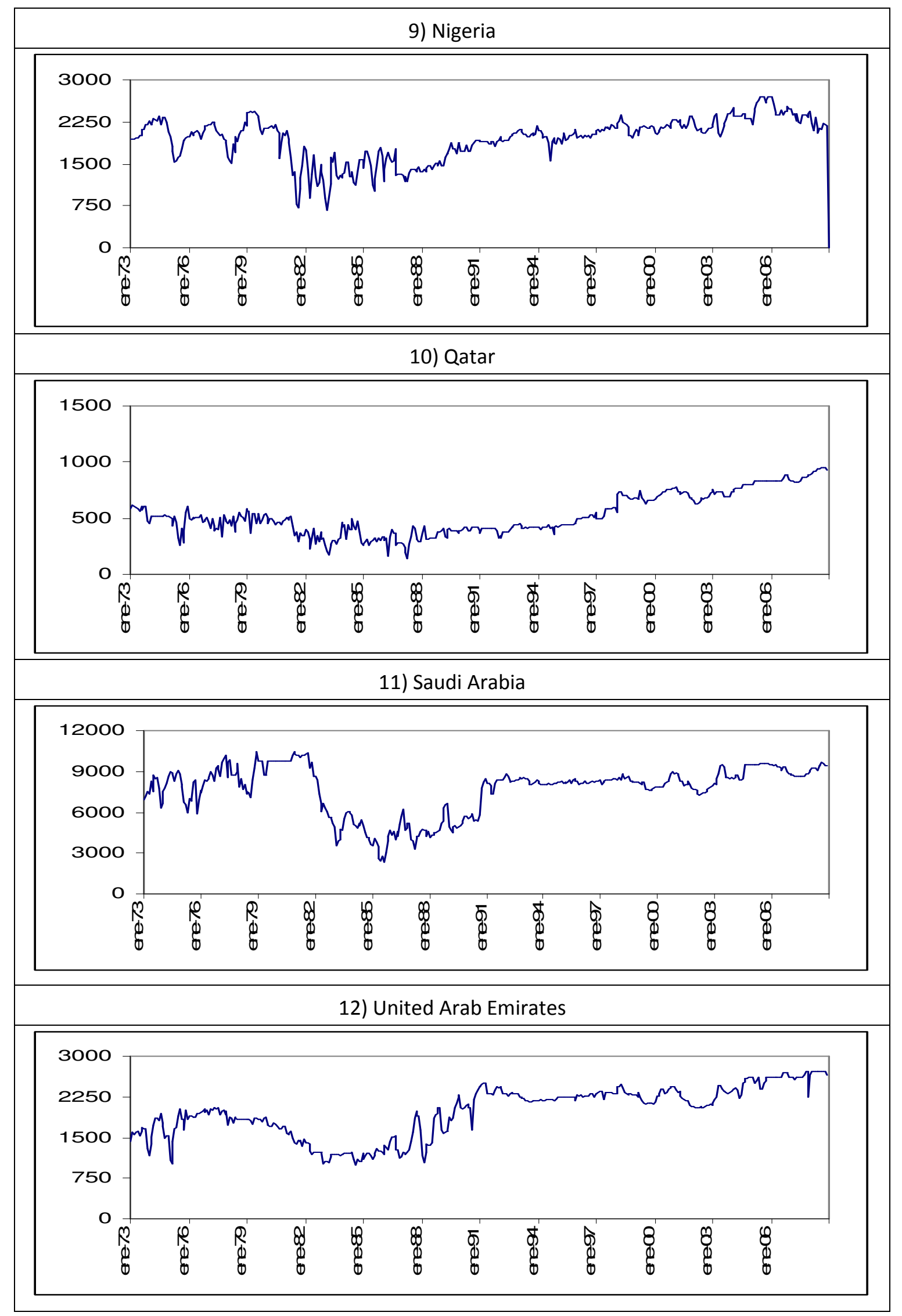




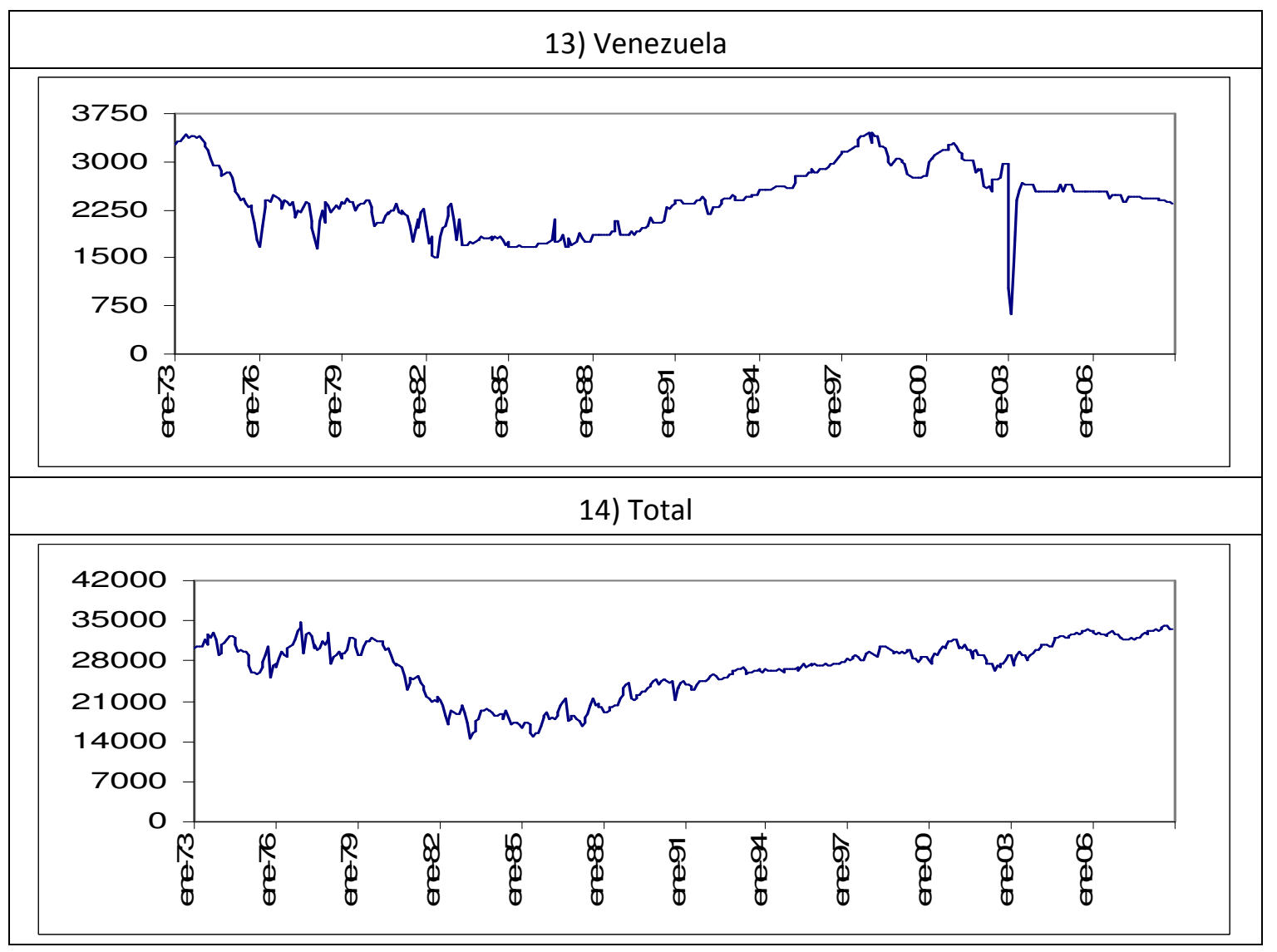

In order to take into account the main feature of the data (i.e., their degree of dependence across time), we first consider the following model,

$$
y_{t}=\beta_{1}+\beta_{2} t+x_{t} ; \quad(1-L)^{d} x_{t}=u_{t},
$$

where $u_{t}$ is $I(0)$, defined first as a white noise process, and then allowing some type of weak autocorrelation structure. The above model includes the standard cases examined in the literature. For example, if $d=0$, we have a deterministic trend model with $I(0)$ disturbances, while if $d=1$, the classical unit root model. However, allowing $d$ to be a real value, we can also examine the possibility of fractional integration. As earlier mentioned, the parameter $d$ is an indicator of the degree of long range dependence, and the higher is the value of $d$, the higher is the level of association between the observations.

Table 2 displays the estimates of the fractional differencing parameter, $d$, in the model given by (6) assuming that the disturbances $u_{t}$ are white noise. We display the estimates of $d$ (in parenthesis within the brackets) along with the 95\% confidence intervals using Robinson's (1994) 
tests, for the three standard cases: (1) no regressors (i.e., $\beta_{1}=\beta_{2}=0$ a priori), ( 2 ) an intercept (i.e., $\beta_{1}$ unknown, and $\beta_{2}=0$ a priori), and (3) an intercept with a linear time trend (i.e., $\beta_{1}$ and $\beta_{2}$ unknown).

Table 2: 95\% Confidence Bands and Estimates of $d$ in a Model with White Noise $u_{t}$

\begin{tabular}{|c|c|c|c|}
\hline & No regressors & An intercept & A linear time trend \\
\hline Algeria & {$\left[\begin{array}{llll}0.870 & (0.931) & 1.007\end{array}\right]$} & {$\left[\begin{array}{llll}0.794 & (0.850) & 0.924\end{array}\right]$} & {$\left[\begin{array}{lll}0.785 & (0.845) & 0.923\end{array}\right]^{*}$} \\
\hline Angola & {$\left[\begin{array}{lll}1.050 & (1.108) & 1.188\end{array}\right]$} & [1.036 (1.087) 1.155] & {$\left[\begin{array}{lll}1.038 & (1.090) & 1.159\end{array}\right]^{*}$} \\
\hline Ecuador & {$\left[\begin{array}{llll}0.706 & (0.777) & 0.861\end{array}\right]$} & {$\left[\begin{array}{llll}0.705 & (0.767) & 0.846]\end{array}\right.$} & {$\left[\begin{array}{llll}0.686 & (0.758) & 0.843\end{array}\right]^{*}$} \\
\hline Indonesia & {$\left[\begin{array}{llll}0.928 & (0.980) & 1.046\end{array}\right]$} & {$\left[\begin{array}{lll}0.791 & (0.842) & 0.906\end{array}\right]^{*}$} & {$\left[\begin{array}{lll}0.787 & (0.840) & 0.905\end{array}\right]$} \\
\hline Iran & {$\left[\begin{array}{llll}0.915 & (0.982) & 1.067\end{array}\right]$} & {$[0.879(0.959) 1.063]^{*}$} & {$[0.880(0.959)$ 1.063] } \\
\hline Iraq & {$\left[\begin{array}{lll}0.836 & (0.903) & 0.987\end{array}\right]$} & {$[0.810(0.880) 0.968]^{*}$} & {$\left[\begin{array}{llll}0.810 & (0.880) & 0.968\end{array}\right]$} \\
\hline Kuwait & {$\left[\begin{array}{llll}0.758 & (0.811) & 0.875\end{array}\right]$} & {$\left[\begin{array}{llll}0.739 & (0.791) & 0.852\end{array}\right]^{*}$} & {$\left[\begin{array}{llll}0.744 & (0.793) & 0.854]\end{array}\right.$} \\
\hline Libya & {$[0.937$ (1.008) 1.095$]$} & {$[0.988(1.074) 1.183]^{*}$} & [0.988 (1.074) 1.183] \\
\hline Nigeria & {$\left[\begin{array}{llll}0.866 & (0.937) & 1.028\end{array}\right]$} & {$\left[\begin{array}{lll}0.788 & (0.876) & 0.992\end{array}{ }^{*}\right.$} & {$[0.787(0.876)$ 0.992] } \\
\hline Qatar & {$\left[\begin{array}{llll}0.733 & (0.782) & 0.843\end{array}\right]$} & {$[0.657(0.694) 0.742]$} & {$\left[\begin{array}{llll}0.641 & (0.681) & 0.732\end{array}\right]^{*}$} \\
\hline Saudi Arabia & {$\left[\begin{array}{llll}0.918 & (0.975) & 1.045\end{array}\right]$} & {$\left[\begin{array}{lll}0.863 & (0.924) & 0.999\end{array}\right]^{*}$} & {$\left[\begin{array}{lll}0.863 & (0.924) & 0.999\end{array}\right]$} \\
\hline U.A.E. & {$\left[\begin{array}{llll}0.881 & (0.949) & 1.034\end{array}\right]$} & {$\left[\begin{array}{lll}0.805 & (0.878) & 0.974\end{array}\right]^{*}$} & {$\left[\begin{array}{lll}0.804 & (0.878) & 0.974]\end{array}\right.$} \\
\hline Venezuela & {$\left[\begin{array}{llll}0.893 & (0.968) & 1.064\end{array}\right]$} & {$\left[\begin{array}{lll}0.830 & (0.925) & 1.058\end{array}\right]^{*}$} & {$\left[\begin{array}{llll}0.843 & (0.925) & 1.058\end{array}\right]$} \\
\hline Total & {$[0.916(0.973) 1.043]$} & {$\left[\begin{array}{lll}0.838 & (0.889) & 0.955\end{array}\right]^{*}$} & {$\left[\begin{array}{llll}0.837 & (0.888) & 0.955\end{array}\right]$} \\
\hline
\end{tabular}

In bold and with an asterisk the estimates of $d$ where the deterministic terms are statistically significant.

We observe from Table 2 that all the estimates are above 0.5 , implying long memory and a nonstationary behaviour, and the results seem to be robust across the different types of deterministic terms. ${ }^{7}$ We present in bold type and with an asterisk the cases where the deterministic terms are statistically significant. We note that for Algeria, Angola, Ecuador, and Qatar, the time trend is significant. For the remaining cases, only an intercept appears significant in the regression models. If we focus now on the estimates of $d$, we observe that only for Angola, the value of $d$ is found to be statistically significantly above 1 . For another three countries, Iran, Libya, and Venezuela, the unit root null (i.e., $d=1$ ) cannot statistically be rejected, while for the remaining nine countries (and for the total production series), the orders of integration are strictly smaller than 1 , ranging from $d=0.681$ (Qatar) to $d=0.924$ (Saudi Arabia). 
Table 3: $95 \%$ Confidence Bands and Estimates of $d$ in a Model with Autocorrelated (Bloomfield) $u_{t}$

\begin{tabular}{|c|c|c|c|}
\hline & No regressors & An intercept & A linear time trend \\
\hline Algeria & {$[0.790(0.891)$ 1.010] } & {$\left[\begin{array}{llll}0.720 & (0.795) & 0.871]\end{array}\right.$} & {$\left[\begin{array}{llll}0.694 & (0.764) & 0.867]\end{array}\right.$} \\
\hline Angola & {$\left[\begin{array}{llll}0.938 & (0.992) & 1.067]\end{array}\right.$} & {$[0.977(1.033) 1.112]$} & {$[0.977(1.041) 1.116]$} \\
\hline Ecuador & {$\left[\begin{array}{llll}0.589 & (0.722) & 0.892]\end{array}\right.$} & {$\left[\begin{array}{llll}0.640 & (0.738) & 0.921]\end{array}\right.$} & {$\left[\begin{array}{llll}0.568 & (0.709) & 0.920\end{array}\right.$} \\
\hline Indonesia & {$\left[\begin{array}{llll}0.902 & (0.987) & 1.098\end{array}\right]$} & {$\left[\begin{array}{lll}0.757 & (0.836) & 0.929\end{array}\right]^{*}$} & {$\left[\begin{array}{llll}0.752 & (0.828) & 0.928\end{array}\right]$} \\
\hline Iran & {$[0.774(0.867) 0.992]$} & {$\left[\begin{array}{lll}0.671 & (0.748) & 0.861\end{array}\right]^{*}$} & {$\left[\begin{array}{llll}0.682 & (0.757) & 0.855\end{array}\right]$} \\
\hline Iraq & {$[0.689(0.768) 0.886]$} & {$[0.631(0.723) 0.829]^{*}$} & {$\left[\begin{array}{llll}0.631 & (0.723) & 0.830\end{array}\right]$} \\
\hline Kuwait & {$[0.761(0.849)$ 0.971] } & {$[0.790(0.883) 1.019]^{*}$} & {$\left[\begin{array}{llll}0.793 & (0.891) & 1.019\end{array}\right]$} \\
\hline Libya & {$[0.792(0.893) 1.041]$} & {$\left[\begin{array}{lll}0.692 & (0.799) & 0.928\end{array}\right]^{*}$} & {$\left[\begin{array}{llll}0.704 & (0.800) & 0.929\end{array}\right]$} \\
\hline Nigeria & {$[0.689(0.783) 0.892]$} & {$\left[\begin{array}{lll}0.547 & (0.611) & 0.707\end{array}\right]^{*}$} & {$\left[\begin{array}{llll}0.530 & (0.607) & 0.706\end{array}\right]$} \\
\hline Qatar & {$\left[\begin{array}{llll}0.752 & (0.837) & 0.930\end{array}\right]$} & {$\left[\begin{array}{lll}0.698 & (0.753) & 0.831\end{array}\right]^{*}$} & {$\left[\begin{array}{llll}0.676 & (0.738) & 0.819\end{array}\right]$} \\
\hline Saudi Arabia & {$\left[\begin{array}{llll}0.872 & (0.968) & 1.080]\end{array}\right.$} & {$\left[\begin{array}{lll}0.798 & (0.889) & 1.012\end{array}\right]^{*}$} & {$\left[\begin{array}{llll}0.798 & (0.889) & 1.012]\end{array}\right.$} \\
\hline U.A.E. & {$\left[\begin{array}{llll}0.747 & (0.828) & 0.960\end{array}\right]$} & {$\left[\begin{array}{lll}0.649 & (0.727) & 0.837\end{array}\right]$} & {$\left[\begin{array}{llll}0.632 & (0.718) & 0.829\end{array}\right]$} \\
\hline Venezuela & {$\left[\begin{array}{lll}0.677 & (0.778) & 0.888\end{array}\right]$} & {$\left[\begin{array}{llll}0.532 & (0.598) & 0.680]\end{array}\right.$} & {$\left[\begin{array}{lll}0.548 & (0.618) & 0.692\end{array}\right]$} \\
\hline Total & {$\left[\begin{array}{llll}0.867 & (0.960) & 1.068]\end{array}\right.$} & {$\left[\begin{array}{lll}0.800 & (0.872) & 0.952\end{array}\right]^{*}$} & {$\left[\begin{array}{llll}0.799 & 0.871) & 0.951\end{array}\right]$} \\
\hline
\end{tabular}

In bold and with an asterisk the estimates of $d$ where the deterministic terms are statistically significant.

In Table 3, we report the results under the assumption that the disturbances $\left(\mathrm{u}_{\mathrm{t}}\right.$ in (6)) are weakly autocorrelated. However, instead of imposing a classical autoregressive model, whose parameters may be competing with $\mathrm{d}$ in describing the time dependence, we use a less conventional approach based on the exponential spectral model of Bloomfield (1973). This is a non-parametric approach that produces autocorrelations decaying exponentially as in the $\mathrm{AR}(\mathrm{MA})$ case; however, the parameters are stationary for all values, and approximate fairly well ARMA structures with a large number of parameters. ${ }^{8}$ The time trend coefficients are now significant in the cases of Algeria, Angola, Ecuador, UAE and Venezuela. The only estimated value of $d$ which is above 1 is again Angola, though now the unit root cannot be rejected. This hypothesis cannot be rejected either in the cases of Kuwait and Saudi Arabia. For the rest of the countries, $\mathrm{d}$ is found to be strictly smaller than 1 , thus implying mean reversion. Here, the lowest degree of integration occurs for Nigeria $(d=0.611)$, followed by Venezuela $(\mathrm{d}=0.618)$ and Ecuador $(\mathrm{d}=0.709)$. 
Summarizing the results presented in these two tables, we can conclude that Angola is the country that presents the highest degree of nonstationarity. For some other countries (Iran, Libya, and Venezuela in case of uncorrelated errors, and Kuwait and Saudi Arabia with autocorrelated disturbances) the unit root model cannot be rejected. However, for the remaining countries (Algeria, Ecuador, Indonesia, Nigeria, Qatar, and UAE) the orders of integration are strictly smaller than 1, implying that shocks affecting the series are transitory, disappearing in the long run though taking a long time to disappear completely.

Table 4: Estimates of the Parameters in the Presence of Outliers with White Noise $u_{t}$

\begin{tabular}{|c|c|c|c|c|c|c|c|}
\hline & \multicolumn{3}{|c}{ With no outliers } & \multicolumn{4}{c|}{ With outliers } \\
\hline \multirow{2}{*}{ Ecuador } & $\mathrm{d}$ & $\alpha$ & $\beta$ & $\mathrm{d}$ & $\alpha$ & $\alpha^{*}$ & $\beta\left(\alpha^{* *}\right)$ \\
& 0.758 & 218.529 & 0.6964 & 0.736 & 216.726 & -65.280 & 0.6995 \\
& {$[0.686,0.843]$} & $(9.087)$ & $(2.192)$ & {$[0.664,0.821]$} & $(9.259)$ & $(-3.211)$ & $(2.514)$ \\
\hline \multirow{2}{*}{ Indonesia } & 0.842 & 1180.69 & --- & 0.837 & 1181.794 & -198.653 & -- \\
& {$[0.791,0.906]$} & 4 & & {$[0.790,0.897]$} & $(28.106)$ & $(-5.997)$ & \\
\hline \multirow{2}{*}{ Iran } & 0.959 & 5806.52 & --- & 0.885 & 5797.451 & -1833.45 & -540.698 \\
& {$[0.879,1.063]$} & 8 & & {$[0.825,0.964]$} & $(22.009)$ & $(-9.458)$ & $(-2.708)$ \\
\hline \multirow{2}{*}{ Iraq } & 0.880 & 1581.03 & --- & 0.877 & 1582.712 & -256.523 & -826.281 \\
& {$[0.810,0.968]$} & 4 & & {$[0.809,0.964]$} & $(5.178)$ & $(-2.136)$ & $(-3.545)$ \\
\hline \multirow{2}{*}{ Kuwait } & 0.791 & 3528.10 & --- & 0.788 & 3522.814 & -115.822 & -- \\
& {$[0.739,0.852]$} & 2 & & {$[0.736,0.850]$} & $(17.324)$ & $(-2.755)$ & \\
\hline \multirow{2}{*}{ Saudi Ar. } & 0.924 & 6928.86 & --- & 0.923 & 7075.951 & -595.473 & - \\
& {$[0.863,0.999]$} & 9 & & {$[0.863,0.999]$} & $(17.232)$ & $(-1.755)$ & - \\
\hline \multirow{2}{*}{ Venezuela } & 0.925 & 3270.16 & --- & 0.851 & 3260.510 & -723.521 & - \\
& {$[0.830,1.058]$} & 1 & & {$[0.778,0.956]$} & $(24.293)$ & $(-6.926)$ & - \\
\hline
\end{tabular}

For Ecuador, the outlier takes place at April, 1987; for Indonesia at February, 1983; for Iran there are two outliers, one at January and February, 1979, and at October, 1980; for Iraq, the two outliers are at February-May, 1991, and at April, 2003; for Kuwait, at February-May, 1991; for Saudi Arabia, at August, 1985; and for Venezuela at January 2003. 
Table 5: Estimates of Parameters in the Presence of Outliers with Autocorrelated $u_{t}$

\begin{tabular}{|c|c|c|c|c|c|c|c|}
\hline & \multicolumn{3}{|c|}{ With no outliers } & \multicolumn{4}{c|}{ With outliers } \\
\hline \multirow{2}{*}{ Ecuador } & $\mathrm{d}$ & $\alpha$ & $\beta$ & $\mathrm{d}$ & $\alpha$ & $\alpha^{*}$ & $\beta\left(\alpha^{* *}\right)$ \\
& 0.709 & 214.237 & 0.7034 & 0.736 & 216.726 & -65.280 & 0.6995 \\
& {$[0.568,0.920]$} & $(9.254)$ & $(2.897)$ & {$[0.595,0.930]$} & $(9.259)$ & $(-3.211)$ & $(2.514)$ \\
\hline \multirow{2}{*}{ Indonesia } & 0.836 & 1182.00 & --- & 0.885 & 1172.319 & -193.366 & --- \\
& {$[0.757,0.929]$} & 9 & & {$[0.808,0.981]$} & $(27.499)$ & $(-5.983)$ & \\
\hline \multirow{2}{*}{ Iran } & 0.748 & 5716.92 & --- & 0.837 & 5782.898 & -1899.21 & -556.382 \\
& {$[0.671,0.861]$} & 9 & & {$[0.770,0.952]$} & $(22.305)$ & $(-9.703)$ & $(-2.725)$ \\
\hline \multirow{2}{*}{ Iraq } & 0.723 & 1693.04 & --- & 0.740 & 1678.649 & -300.310 & -892.617 \\
& {$[0.631,0.829]$} & 2 & & {$[0.652,0.855]$} & $(5.951)$ & $(-2.305)$ & $(-3.618)$ \\
\hline \multirow{2}{*}{ Kuwait } & 0.883 & 3660.13 & --- & 0.881 & 3657.805 & -86.725 & - \\
& {$[0.790,1.019]$} & 4 & & {$[0.781,1.010]$} & $(17.371)$ & $(-2.563)$ & - \\
\hline \multirow{2}{*}{ Saudi Ar. } & 0.889 & 6959.31 & --- & 0.889 & 6959.327 & -553.614 & -- \\
& {$[0.798,1.012]$} & 9 & & {$[0.798,1.011]$} & $(16.520)$ & $(-1.738)$ & \\
\hline \multirow{2}{*}{ Venezuela } & 0.618 & 3127.74 & -1.324 & 0.765 & 3243.993 & -801.197 & -1.560 \\
& {$[0.548,0.692]$} & 1 & $(-1.654)$ & {$[0.704,0.841]$} & $(25.132)$ & $(-7.386)$ & $(-1.884)$ \\
\hline
\end{tabular}

For Ecuador, the outlier takes place at April, 1987; for Indonesia at February, 1983; for Iran there are two outliers, one at January and February, 1979, and at October, 1980; for Iraq, the two outliers are at February-May, 1991, and at April, 2003; for Kuwait, at February-May, 1991; for Saudi Arabia, at August, 1985; and for Venezuela at January 2003.

The results presented so far may be biased because of the presence of breaks and/or outliers (see Gil-Alana, 2003; 2005). ${ }^{9}$ Tables 4 and 5 address the issue of outliers in the data. We identify outliers in seven countries (Ecuador, Indonesia, Iran, Iraq, Kuwait, Saudi Arabia, and Venezuela) and use dummy variables to describe them. ${ }^{10}$ The results including these dummies in the regression model (3) and using white noise $u_{t}$ are reported in Table 4 and using the autocorrelated model of Bloomfield (1973) reported in Table $5 .{ }^{11}$

The results in the left-hand sides of Tables 4 and 5 report the estimates of the model parameters under the assumption that there are no outliers. The results in the right-hand side refer to the estimates assuming the existence of one or two outliers depending on the series. Starting with the results based on white noise disturbances (in Table 4) we observe a reduction in the degree of integration in all the countries once the outliers are taken into account. Thus, for example, for Iran and Venezuela the unit root null hypothesis cannot be rejected if no outliers are considered, however, including them, this hypothesis is rejected in the two countries in favour of orders of integration smaller than 1 . This is less clear if the 
disturbances are autocorrelated as shown in Table 5. Here, we note higher orders of integration with outliers for the cases of Ecuador, Indonesia, Iran, Iraq, and Venezuela; more or less the same estimates in case of Saudi Arabia, and a slight reduction only for Kuwait. In general, there are no substantial differences if outliers are taken into account. Mean reversion seems to take place in all the countries examined with the exceptions of Kuwait and Saudi Arabia where the unit root null cannot be rejected.

Table 6: Estimates of $d$ in the Presence of Structural Breaks

\begin{tabular}{|c|c|c|c|c|c|}
\hline & N. Breaks & Bk.Dates & \multicolumn{3}{|c|}{ Parameter estimates } \\
\hline Algeria & 0 & --- & \multicolumn{3}{|c|}{$d=0.764 ; \quad \alpha=1123.33 ; \quad \beta=1.624$} \\
\hline Angola & 0 & --- & \multicolumn{3}{|c|}{$d=1.041 ; \quad \alpha=158.438 ; \quad \beta=4.316$} \\
\hline Ecuador & $1+$ outlier & Sept-03 & $\mathrm{d}_{1}=0.81 ; \alpha_{1}=225.9 ; \alpha_{1}^{*}=-57.86$ & \multicolumn{2}{|c|}{$\mathrm{d}_{2}=1.090 ; \quad \alpha_{2}=475.610$} \\
\hline Indonesia & 0 & -- & \multicolumn{3}{|c|}{$d=0.842 ; \quad \alpha=1180.694$} \\
\hline Iran & 1 & Nov-78 & $\mathrm{d}_{1}=0.922 ; \quad \alpha_{1}=5809.72$ & \multicolumn{2}{|c|}{$d_{2}=1.023 ; \quad \alpha_{2}=3543.88$} \\
\hline Iraq & 2 & $\begin{array}{l}\text { Oct-80 } \\
\text { Aug-90 }\end{array}$ & \multicolumn{2}{|c|}{\begin{tabular}{c|c}
$d_{1}=0.642 ;$ & $d_{2}=1.018 ;$ \\
$\alpha_{1}=1661.3 ;$ & $\alpha_{2}=109.48 ;$ \\
$\beta_{1}=-16.4$ & $\beta_{2}=28.70$
\end{tabular}} & $\begin{array}{l}d_{3}=0.740 \\
\alpha_{3}=866.9\end{array}$ \\
\hline Kuwait & 0 & --- & \multicolumn{3}{|c|}{$d=0.791 ; \quad \alpha=3528.102$} \\
\hline Libya & 1 & Jan-83 & $d_{1}=1.141 ; \quad \alpha_{1}=2300.59$ & \multicolumn{2}{|c|}{$\mathrm{d}_{2}=0.978 ; \quad \alpha_{2}=1125.79$} \\
\hline Nigeria & 1 & Jul-81 & $d_{1}=1.055 ; \quad \alpha_{1}=1934.64$ & \multicolumn{2}{|c|}{$\mathrm{d}_{2}=0.890 ; \quad \alpha_{2}=809.569$} \\
\hline Qatar & 1 & May-86 & $\begin{array}{c}d_{1}=0.69 ; \\
\alpha_{1}=586.26 ; \quad \beta_{1}=-1.98\end{array}$ & \multicolumn{2}{|c|}{$\begin{array}{c}d_{1}=0.95 \\
\alpha_{2}=-22.02 ; \beta_{2}=-1.75\end{array}$} \\
\hline Saudi Arabic & 2 & $\begin{array}{l}\text { Mar-82 } \\
\text { Sep-90 }\end{array}$ & \begin{tabular}{c|r}
$d_{1}=0.708 ;$ & $d_{2}=0.9$ \\
$\alpha_{1}=7249.07$ & $\alpha_{2}=725$ \\
\end{tabular} & & $\begin{array}{c}d_{3}=1.034 ; \\
\alpha_{3}=7651.05\end{array}$ \\
\hline U.A.E. & 1 & Sep-90 & $\mathrm{d}_{1}=0.993 ; \quad \alpha_{1}=1417.78$ & \multicolumn{2}{|c|}{$\mathrm{d}_{2}=0.998 ; \quad \alpha_{2}=2198.82$} \\
\hline Venezuela & $1+$ outlier & Sep-86 & $d_{1}=0.994 ; \quad \alpha_{1}=32715992$ & \multicolumn{2}{|c|}{$\begin{array}{c}\mathrm{d}_{2}=0.97 ; \\
\alpha_{2}=1760.7 ; \alpha_{2}^{*}=-624.3\end{array}$} \\
\hline Total & 1 & Sep-86 & $\mathrm{d}_{1}=0.955 ; \quad \alpha_{1}=30185.31$ & \multicolumn{2}{|c|}{$d_{2}=1.041 ; \quad \alpha_{2}=17556.21$} \\
\hline
\end{tabular}

Finally, in the case of structural breaks, we implement the method of Gil-Alana (2008) described in the previous section and in Appendix 2. We employ one and two breaks and choose the appropriate number of breaks using likelihood information criteria (see Appendix 2). Note that a crucial distinction between breaks and outliers in the context of the present work is that in the case of the breaks we allow for different orders of integration before and after the breaks. On the contrary, in the case of outliers, the degree of dependence remains unaltered across the sample. The results displayed in Table 6 show no breaks for the cases of Algeria, Angola, Indonesia, and 
Kuwait. One single break for Iran, Libya, Nigeria, Qatar, UAE, Ecuador, and Venezuela, in the latter two countries including also outliers, and two breaks for Iraq and Saudi Arabia.

Notice in Table 6 that the break dates substantially change from one series to another. Thus, there is an early break in Iran (November 1978) due to the exile of the Shah of Iran and the associated revolution. For Iraq (October 1980 and August 1990), the October 1980 break is attributed to the Iranian revolution and the August 1990 break to Iraq's occupation of Kuwait (i.e. first Gulf War). In the case of Nigeria (July 1981) the observed break is attributed to the longstanding border dispute between Nigeria and Cameroon which generates the first of several crises from May 15, 1981 to July 24, 1981. In Saudi Arabia (March 1982 and September 1990), the March 1982 break is affiliated with the curtailment of production and an atmosphere of recrimination between OPEC producers over cheating on production quotas which marked the period March 1982 to March 1983 (see Ramazani, 1988) while the September 1990 break is attributed to the first Gulf War. The break in the case of Libya (January 1983) is related to U.S. military attacks in response to Libya's support for international terrorism. For Qatar, (May 1986) the break pertains to the continuing dispute with Bahrain concerning the nearby Hawar Islands, which resulted in Qatar troops briefly occupying a coral reef which was being reclaimed from the sea. For Venezuela (September 1986), the observed break is due to the halt in production in light of low oil prices. The UAE (September 1990) also experienced a break due to the first Gulf War. Finally, the latest break occurs in Ecuador (September 2003) related to tensions between the indigenous people and oil companies located in Ecuador.

If we focus now on the orders of integration, we first notice that for the countries where there are no breaks (Algeria, Angola, Indonesia, and Kuwait), we obtain mean reversion in three of them (Algeria $d=0.764$; Indonesia $d=0.842$; and Kuwait, $d=0.791$ ), however, for Angola with $d=$ 1.041, the unit root null hypothesis cannot be rejected. For those countries with a single break, we observe a significant increase in the degree of integration in Ecuador, Iran, UAE, Venezuela, and for the total production series; in all these countries mean reversion is observed in the first subsample 
and the unit root cannot be rejected after the break. However, for Libya and Nigeria there is a decrease in the value of $d$ though the unit root cannot be rejected in any of the two subsamples. Finally, there are two countries where two breaks are observed: Iraq and Saudi Arabia. In the former country, the orders of integration are $d_{1}=0.642, d_{2}=1.018$ and $d_{3}=0.740$, with the presence of a unit root rejected in favour of mean reversion in the first and third subsamples, and failure to reject a unit root in the second subsample corresponding to the decade of the 1980s. In case of Saudi Arabia, the order of integration increases across time $\left(d_{1}=0.708, d_{2}=0.941\right.$, and $\left.d_{3}=1.034\right)$ with the failure to reject a unit root during the third subsample.

\section{Discussion}

We have presented in Section 4 results based on fractional integration using three different approaches: a) a model with no outliers and no breaks, b) a model with outliers, and c) a model with outliers and breaks.

The results can be summarized as follows: if no breaks and no outliers are taken into account, most of the fractional differencing parameters are in the interval $(0.5,1)$ implying long memory and mean reverting behaviour, with shocks disappearing in the long run. The exceptions are Angola, and also Kuwait and Saudi Arabia (with white noise errors) and Iran, Libya and Venezuela (with autocorrelated errors) where the unit root cannot be rejected, and thus suggesting that shocks have permanent effects on these countries. Thus, according to this specification, in the event of an exogenous shock, stronger policy measures must be adopted in countries like Angola, Kuwait, Saudi Arabia, Iran, Libya and Venezuela than in others like Algeria, Ecuador, Indonesia, Iraq, Nigeria, Qatar and UAE to recover the series to its original trend. Allowing for outliers, these are found to be statistically significant in the cases of Ecuador, Indonesia, Iran, Iraq, Kuwait, Saudi Arabia and Venezuela, and the conclusions remain almost the same, with values close to but smaller than 1 in most cases. Evidence of unit roots is only obtained for Kuwait and Saudi Arabia if the disturbances are autocorrelated. Finally, we permit breaks and/or outliers and employed the methodology 
proposed by Gil-Alana (2008). The results here are conclusive: four countries (Algeria, Angola, Indonesia and Kuwait) do not present breaks, and evidence of mean reversion (i.e. $d<1$ ) is obtained in three of them. Only Angola displays lack of mean reversion. Another group of six countries presents a single break: Ecuador, Iran, UAE, Venezuela, Libya and Nigeria, and evidence of mean reversion is only observed in the first four countries during the period previous to the breaks. Finally, two countries (Iraq and Saudi Arabia) present two breaks and evidence of permanent shocks (i.e. unit roots) are observed during the second subsample in the former country and in the last subsample in the case of Saudi Arabia.

Maslyuk and Smyth (2009) postulate that countries that have large proven oil reserves, one would expect oil production would be stationary given such countries would be able to maintain a constant supply during periods of economic or political turmoil. In light of the proven oil reserves reported in Table 1, this hypothesis is not supported given that the countries with the largest proven oil reserves do not display mean reversion across the periods associated with structural breaks. This finding confirms the conclusion reached by Maslyuk and Smyth (2009). Alternatively, Narayan et al. (2008) suggest that countries with high volatility in production are more likely not to exhibit mean reversion in oil production. The rationale is that countries with volatile production deviations from the long-run equilibrium path due to shocks will be larger and hence the departure from the longrun equilibrium path will be less likely to be temporary. As shown in Table 7 , the assertion by Narayan et al. (2008) that countries with high volatility in production correlates will have the presence of a unit root (i.e. permanent effects of shocks) is not substantiated with the findings of mean reversion in a majority of the OPEC countries. 
Table 7: Oil Production Volatility

\begin{tabular}{|c|c|c|c|}
\hline Country & Std. Dev. & Country & Std. Dev. \\
\hline Algeria & 262.103 & Libya & 342.227 \\
\hline Angola & 448.961 & Nigeria & 379.255 \\
\hline Ecuador & 115.545 & Qatar & 182.333 \\
\hline Indonesia & 192.593 & Saudi Arabia & 1784.857 \\
\hline Iran & 1236.234 & U.A.E. & 463.433 \\
\hline Iraq & 889.804 & Venezuela & 488.499 \\
\hline Kuwait & 646.942 & Total & 4915.304 \\
\hline
\end{tabular}

Oil production volatility measured by the standard deviation for the period 1973:1 to 2008:10.

\section{Concluding Remarks}

Unlike previous studies on oil production employing traditional unit root integrated models or even threshold unit root tests, this study adopts a fractional integration model adopted by Caporale and Gil-Alana $(2007 ; 2008)$ which incorporates breaks and outliers in the analysis. Specifically, we present different specifications based on fractional integration, first with no breaks, and then allowing outliers and breaks to describe time series dependence and other implicit dynamics of oil production in OPEC countries. The results indicate that the standard methods employed in the literature, based on stationary I(0) or non-stationary I(1) models are clearly rejected in favor of fractional degrees of integration. Evidence of long memory $(d>0)$ is obtained in all cases, with orders of integration ranging from 0.642 (Iraq during the first subsample, January 1973 - October 1980) to 1.141 (Libya, first subsample: January 1973 - January 1981).

However, the results substantially vary from one country to another. Thus, for Algeria, Indonesia, and Kuwait, we do not observe breaks, and mean reversion is obtained in the three countries with their orders of integration strictly below 1 , which indicates that shocks are transitory and mean reverting, disappearing in the long run. Mean reversion is also observed in some countries in which a single break is required; for example, Iran, Qatar, UAE, Ecuador, and Venezuela during the first subsamples, and in the latter two countries outliers seem to be present as well. Finally, we observe two countries with two structural breaks, Iraq and Saudi Arabia. In the former country, 
mean reversion occurs during the sample period except for the period of the 1980s, and in Saudi Arabia during the period before the second break in September 1990. These results confirm the high degree of persistence in each series.

Thus, the results indicate that shocks affecting the structure of OPEC oil production (based on the estimates of $d$ in all tables), will have persistent effects in the long run for all countries, and in some cases the effects are expected to be permanent. Indeed, the maximum rate of oil production is determined by operational capacity which in turn is influenced by the existing capital structure. Hence, it is not surprising to observe a high degree of persistence in terms of oil production. The incorporation of outliers and structural breaks into the analysis highlights the role of exogenous events either political or economic, which may reduce production levels below operational capacity. As a consequence, disruptions in oil production and supply will have a persistent impact on economic activity as such shocks will be transmitted to other sectors of the economy. Therefore, it is crucial for policy makers to distinguish the nature of the shock (i.e. transitory or persistent) since the policy actions may differ as to the type of shock. In case of values of $d$ equal to or above 1 , stabilization policies in restoring production levels to equilibrium levels will be required; otherwise, the implications for oil production and supply will persist forever. On the other hand, for countries with values of $d$ below 1 , shocks will disappear in the long run as production will return to equilibrium levels over time without the need for stabilization efforts.

In summary, it is clear that taking first differences in the oil production of OPEC countries under the assumption of a unit root, may lead in some cases to series that are over-differenced, and subsequently such a procedure may result in inappropriate policy actions. Similarly, the standard analysis based on cointegration techniques and involving oil productioni should be examined in the more general context of fractional cointegration (Robinson and Hualde, 2003; Johansen, 2008). Second, persistence behavior is another characteristic of these data although for some countries the adjustment process takes a long time to disappear in which case an active oil policy stance is required to restore oil production levels. Third, outliers do not alter the main conclusions of this 
study though in two countries (Ecuador and Venezuela) outliers should be considered even in the context of structural breaks. Fourth, the breaks in oil production are specific to each country or common to OPEC policy, signifying that there are specific events that affect each country's oil production and common elements to many OPEC countries. 


\section{Appendix 1: Robinson's (1994) Parametric Approach}

The LM test of Robinson (1994) for testing $H_{0}: d=d_{0}$ in (2) and (3) is

$$
\hat{r}=\frac{T^{1 / 2}}{\hat{\sigma}^{2}} \hat{A}^{-1 / 2} \hat{a}
$$

where $\mathrm{T}$ is the sample size and:

$$
\begin{aligned}
& \hat{a}=\frac{-2 \pi}{T} \sum_{j=1}^{T-1} \psi\left(\lambda_{j}\right) g\left(\lambda_{j} ; \hat{\tau}\right)^{-1} I\left(\lambda_{j}\right) ; \quad \hat{\sigma}^{2}=\sigma^{2}(\hat{\tau})=\frac{2 \pi}{T} \sum_{j=1}^{T-1} g\left(\lambda_{j} ; \hat{\tau}\right)^{-1} I\left(\lambda_{j}\right) \\
& \hat{A}=\frac{2}{T}\left(\sum_{j=1}^{T-1} \psi\left(\lambda_{j}\right)^{2}-\sum_{j=1}^{T-1} \psi\left(\lambda_{j}\right) \hat{\varepsilon}\left(\lambda_{j}\right)^{\prime} \times\left(\sum_{j=1}^{T-1} \hat{\varepsilon}\left(\lambda_{j}\right) \hat{\varepsilon}\left(\lambda_{j}\right)^{\prime}\right)^{-1} \times \sum_{j=1}^{T-1} \hat{\varepsilon}\left(\lambda_{j}\right) \psi\left(\lambda_{j}\right)\right)
\end{aligned}
$$

$\psi\left(\lambda_{j}\right)=\log \left|2 \sin \frac{\lambda_{j}}{2}\right| ; \quad \hat{\varepsilon}\left(\lambda_{j}\right)=\frac{\partial}{\partial \tau} \log g\left(\lambda_{j} ; \hat{\tau}\right) ; \quad \lambda_{j}=\frac{2 \pi j}{T} ; \quad \hat{\tau}=\arg \min \sigma^{2}(\tau)$.

$\hat{\mathrm{a}}$ and $\hat{\mathrm{A}}$ in the above expressions are obtained through the first and second derivatives of the loglikelihood function with respect to $d$ (see Robinson, 1994, page 1422 , for further details). $\mathrm{I}\left(\lambda_{\mathrm{j}}\right)$ is the periodogram of $u_{t}$ evaluated under the null, i.e.:

$$
\begin{gathered}
\hat{u}_{t}=(1-L)^{d_{o}} y_{t}-\hat{\beta}^{\prime} w_{t} ; \\
\hat{\beta}=\left(\sum_{t=1}^{T} w_{t} w_{t}\right)^{-1} \sum_{t=1}^{T} w_{t}(1-L)^{d_{o}} y_{t} ; \quad w_{t}=(1-L)^{d_{o}} z_{t},
\end{gathered}
$$

$z_{t}=(1, t)^{\top}$, and $g$ is a known function related to the spectral density function of $u_{t}$ :

$$
f\left(\lambda ; \sigma^{2} ; \tau\right)=\frac{\sigma^{2}}{2 \pi} g(\lambda ; \tau), \quad-\pi<\lambda \leq \pi
$$




\section{Appendix 2: Gil-Alana's (2008) Method for Fractional Integration with Breaks}

The model presented in (4) and (5) can also be written as:

$$
\begin{array}{r}
(1-L)^{d_{1}} y_{t}=\beta_{1} \tilde{z}_{t}\left(d_{1}\right)+u_{t}, \quad t=1, \ldots, T_{b}, \\
(1-L)^{d_{2}} y_{t}=\beta_{2} \tilde{z}_{t}\left(d_{2}\right)+u_{t}, \quad t=T_{b}+1, \ldots, T,
\end{array}
$$

where $\tilde{z}_{t}\left(d_{i}\right)=(1-L)^{d_{i}} z_{t}, \mathrm{i}=1,2$. The procedure is based on the least square principle. First we choose a grid for the values of the fractionally differencing parameters $d_{1}$ and $d_{2}$, for example, $d_{i o}=$ $0,0.01,0.02, \ldots, 1, i=1,2$. Then, for a given partition $\left\{T_{b}\right\}$ and given initial $d_{1}, d_{2}$-values, $\left(d_{10}^{(1)}, d_{2 o}^{(1)}\right)$, we estimate the $\alpha$ 's and the $\beta$ 's by minimizing the sum of squared residuals,

$$
\min \sum_{t=1}^{T_{b}}\left[(1-L)^{d_{1 o}^{(1)}} y_{t}-\beta_{1} \tilde{z}_{t}\left(d_{1 o}^{(1)}\right)\right]^{2}+\sum_{t=T_{b}+1}^{T}\left[(1-L)^{d_{2 o}^{(1)}} y_{t}-\beta_{2} \tilde{z}_{t}\left(d_{2 o}^{(1)}\right)\right]^{2}
$$

Let $\hat{\beta}\left(T_{b} ; d_{10}^{(1)}, d_{2 o}^{(1)}\right)$ denote the resulting estimates for partition $\left\{T_{b}\right\}$ and initial values $d_{10}^{(1)}$ and $d_{2 o}^{(1)}$. Substituting these estimated values on the objective function, we have $\operatorname{RSS}\left(T_{b} ; d_{10}^{(1)}, d_{20}^{(1)}\right)$, and minimizing this expression across all values of $d_{10}$ and $d_{20}$ in the grid we obtain $\operatorname{RSS}\left(T_{b}\right)=$ $\arg \min _{\{i, j\}} \operatorname{RSS}\left(\mathrm{T}_{\mathrm{b} ;} \mathrm{d}_{1 \mathrm{o}}^{(\mathrm{i})}, \mathrm{d}_{2 \mathrm{o}}^{(\mathrm{j})}\right)$. Next, the estimated break date, $\hat{\mathrm{T}}_{\mathrm{k}}$, is such that $\hat{T}_{k}=\arg \min { }_{i=1, \ldots, m} \operatorname{RSS}\left(T_{i}\right)$, where the minimization is taken over all partitions $T_{1}, T_{2}, \ldots, T_{m}$, such that $T_{i}-T_{i-1} \geq|\varepsilon T|$. Then, the regression parameter estimates are the associated least-squares estimates of the estimated k-partition, i.e., $\hat{\beta}_{i}=\hat{\beta}_{i}\left(\left\{\hat{T}_{k}\right\}\right)$, and their corresponding differencing parameters, $\hat{\mathrm{d}}_{\mathrm{i}}=\hat{\mathrm{d}}_{\mathrm{i}}\left(\left\{\hat{\mathrm{T}}_{\mathrm{k}}\right\}\right)$, for $\mathrm{i}=1$ and 2 .

The model can be extended to the case of multiple breaks. Thus, we can consider the model,

$$
y_{t}=\alpha_{j}+\beta_{j} t+x_{t} ;(1-L)^{d_{j}} x_{t}=u_{t}, \quad t=T_{j-1}+1, \ldots, T_{j},
$$

for $\mathrm{j}=1, \ldots, \mathrm{m}+1, \mathrm{~T}_{0}=0$ and $\mathrm{T}_{\mathrm{m}+1}=\mathrm{T}$. Then, the parameter $\mathrm{m}$ is the number of changes. The break dates $\left(T_{1}, \ldots, T_{m}\right)$ are explicitly treated as unknown and for $\mathrm{i}=1, \ldots, \mathrm{m}$, we have $\lambda_{\mathrm{i}}=\mathrm{T}_{\mathrm{i}} / \mathrm{T}$, with $\lambda_{1}<\ldots<$ 
$\lambda_{m}<1$. Following the same process as in the previous case, for each $j$-partition, $\left\{T_{1}, \ldots T_{j}\right\}$, denoted $\left\{T_{j}\right\}$, the associated least-squares estimates of $\alpha_{j}, \beta_{j}$ and the $d_{j}$ are obtained by minimizing the sum of squared residuals in the $d_{i}$-differenced models, i.e.,

$$
\sum_{j=1}^{m+1} \sum_{t=T_{j-1}+1}^{T_{j}}(1-L)^{d_{i}}\left(y_{t}-\alpha_{i}-\beta_{i} t\right)^{2},
$$

where $\hat{\alpha}_{i}\left(T_{j}\right), \hat{\beta}_{i}\left(T_{j}\right)$ and $\hat{d}\left(T_{j}\right)$ denote the resulting estimates. Substituting them in the new objective function and denoting the sum of squared residuals as $\operatorname{RSS}_{T}\left(T_{1}, \ldots, T_{m}\right)$, the estimated break dates $\left(\hat{\mathrm{T}}_{1}, \hat{\mathrm{T}}_{2}, \ldots, \hat{\mathrm{T}}_{\mathrm{m}}\right)$ are obtained by $\min { }_{\left(\mathrm{T}_{1}, \mathrm{~T}_{2}, \ldots, \mathrm{T}_{\mathrm{m}}\right)} \mathrm{RSS}_{\mathrm{T}}\left(\mathrm{T}_{1}, \ldots, \mathrm{T}_{\mathrm{m}}\right)$ where the minimization is again obtained over all partition $\left(T_{1}, \ldots, T_{m}\right)$.

The above procedure requires the a priori determination of the number of breaks in the time series. Following standard procedures to select the number of breaks in the context of $I(0)$ processes, Schwarz (1978) proposed the criterion:

$$
\mathrm{SIC}(\mathrm{m})=\ln \left[\mathrm{RSS}_{\mathrm{T}}\left(\hat{\mathrm{T}}_{1}, \ldots, \hat{\mathrm{T}}_{\mathrm{m}}\right) /(\mathrm{T}-\mathrm{m})\right\rfloor+2 \mathrm{p}^{*} \ln (\mathrm{T}) / \mathrm{T},
$$

where $p^{*}$ is the number of unknown parameters. Yao (1988) used the Bayesian criterion:

$$
\operatorname{BIC}(\mathrm{m})=\ln \left[\operatorname{RSS}_{\mathrm{T}}\left(\hat{\mathrm{T}}_{1}, \ldots, \hat{\mathrm{T}}_{\mathrm{m}}\right) / \mathrm{T}\right]+\mathrm{p}^{*} \ln (\mathrm{T}) / \mathrm{T} .
$$

Finally, Yao and Av (1989) proposed a third criterion based on

$$
\mathrm{YIC}(\mathrm{m})=\ln \left[\mathrm{RSS}_{\mathrm{T}}\left(\hat{\mathrm{T}}_{1}, \ldots, \hat{\mathrm{T}}_{\mathrm{m}}\right) / \mathrm{T}\right]+\mathrm{mC}_{\mathrm{T}} / \mathrm{T},
$$

where $C_{T}$ is any sequence satisfying $C_{T} T^{-2 d / k} \rightarrow \infty$ as $T \rightarrow \infty$ for some positive integer $k$.

The estimated number of break dates, $\hat{m}$, is then obtained by minimizing the abovementioned information criteria given $\mathrm{M}$ a fixed upper bound for $\mathrm{m}$. 


\section{Endnotes}

1. Five founding members are Iran, Iraq, Kuwait, Saudi Arabia and Venezuela with nine other members joining later: Qatar (1961); Indonesia (1962) -- suspended its membership in January 2009; Libya (1962); United Arab Emirates (1967); Algeria (1969); Nigeria (1971); Ecuador (1973) -- suspended its membership from December 1992 to October 2007; Angola (2007); and Gabon (1975-1994), see Kaufmann et al (2008).

2. From an econometric viewpoint the two issues are highly related noting that the omission of breaks may spuriously increase the degree of persistence in the data.

3. Smith (2009) provides an excellent discussion of the world oil market with respect to production decisions and its effect on price. Kaufman et al. (2008) on OPEC oil production.

4. See, for example, Lean and Smyth (2009) for the relevance of testing for unit roots.

5. There is also an enormous literature on the causal relationship between energy consumption and economic growth in which preliminary tests for unit roots are undertaken in the estimation of error correction models to infer Granger-causal relationships. See Payne (2010a,b) and Ozturk (2010) for surveys of this literature.

6. In the context of the present work, it should be noted that the ADF test (and also other unit-root testing procedures such as Phillips and Perron (1988) and Kwiatkowski et al (1992)) have very low power if the alternatives are of a fractional form (see Diebold and Rudebusch, 1991; Hassler and Wolters, 1994; Lee and Schmidt, 1996).

7. In the $\mathrm{I}(\mathrm{d})$ context, a series is covariance stationary if $\mathrm{d}<0.5$. If $\mathrm{d} \geq 0.5$, the series is no longer covariance stationary but still mean reverting if $\mathrm{d}<1$.

8. See Gil-Alana (2004) for a paper dealing with fractional integration in the context of Bloomfield disturbances.

9. Some authors claim that fractional integration may be a spurious phenomenon caused by the no-consideration of breaks in the data. (See, e.g., Smith, 2005).

10. They have been identified using standard methods, testing its statistical significance throughout the t-values in the d-differenced processes.

11. We use dummies of form $D_{t}=1 \mathrm{I}\left(t=T^{*}\right)$, where $\mathrm{I}$ is the indicator function and $\mathrm{T}^{*}$ is the time period for the outliers. Other dummies produced insignificant results. 


\section{References}

Altinay, G. and E. Karagol (2004),"Structural Break, Unit Root, and the Causality between Energy Consumption and GDP in Turkey", Energy Economics, 26, 985-994.

Bloomfield, P. (1973), "An Exponential Model in the Spectrum of a Scalar Time Series", Biometrika, 60, 217-226.

Boone, J.P. (2001), "Empirical Evidence for the Superiority of Non-US Oil and Gas Investments", Energy Economics, 23, 211-226.

Breitung, J. (2000), "The Local Power of Some Unit Root Tests for Panel Data" in Baltagi, B.H. editor, Nonstationary Panels, Panel Cointegration, and Dynamic Panels, Elsevier: Amsterdam, 161-177.

Caner, M. and B.E. Hansen (2001), "Threshold Autoregression with a Unit Root", Econometrica, 69, 1555-1596.

Caporale, G.M. and L.A. Gil-Alana (2007), "Nonlinearities and Fractional Integration in the US Unemployment Rate", Oxford Bulletin of Economics and Statistics, 69, 521-544.

Caporale, G.M. and L.A. Gil-Alana (2008), "Modeling Structural Breaks in the US, the UK and Japanese Unemployment Rate", Computational Statistics and Data Analysis, 52, 4998-5013.

Chen, P.F. and C.C. Lee (2007), "Is Energy Consumption Per Capita Broken Stationary? New Evidence from Regional Based Panels", Energy Policy, 35, 3526-3540.

Dahlhaus, R. (1989), "Efficient Parameter Estimation for Self-Similar Process", Annals of Statistics, 17, 1749-1766.

Dickey, D. and W. Fuller (1979), "Distribution of the Estimators for Autoregressive Time Series with a Unit Root", Journal of the American Statistical Association, 74, 427-431.

Diebold, F.X. and A. Inoue (2001), "Long Memory and Regime Switching", Journal of Econometrics, 105, 131-159.

Diebold, F.X., and G.D. Rudebusch (1991), "On the Power of Dickey-Fuller Test against Fractional Alternatives”, Economics Letters, 35, 155-160.

Dixit, A. and R. Pindyck (1994), Investment under Uncertainty, Princeton: Princeton University Press.

Energy Information Administration:

http://www.eia.doe.gov/emeu/international/oilproduction.html.

Fattouh, B. (2007), "OPEC Pricing Power: The Need for a New Perspective", WPM 31, Oxford Institute for Energy Studies.

Gately, D. (2004), “OPEC's Incentive for Faster Output Growth", Energy Journal, 25, 75-96. 
Gil-Alana, L.A. (2003), "Testing of Unit Roots and Other Fractionally Integrated Hypotheses in the Presence of Structural Breaks", Empirical Economics, 28, 101-113.

Gil-Alana, L.A. (2004), "The Use of the Bloomfield Model as an Approximation to ARMA Structures in the Context of Fractional Integration", Mathematical and Computer Modelling, 39, 429-436.

Gil-Alana, L.A. (2005), "Unit and Fractional Roots in the Presence of Abrupt Changes with an Application to the Brazilian Inflation Rates", Empirical Economics, 30, 193-207.

Gil-Alana, L.A. (2008), "Fractional Integration and Structural Breaks at Unknown Periods of Time", Journal of Time Series Analysis, 29, 163-185.

Granger, C.W.J. and N. Hyung (2004), "Occasional Structural Breaks and Long Memory with an Application to the S\&P 500 Absolute Stock Return", Journal of Empirical Finance, 11, 399-421.

Hadri, K. (2000), "Testing for Stationarity in Heterogeneous Panel Data", Econometrics Journal, 3, 148-161.

Hasslers, U., and J. Wolters (1994). "On the Power of Unit Root Tests against Fractional Alternatives". Economics Letters, 45, 1-5.

Höök, M. and K. Aleklett (2008), "A Decline Rate Study of Norwegian Oil Production", Energy Policy, $36,4662-4671$.

Hsu, Y.C., C.C. Lee, C.C. Lee (2008), "Revisited: Are Shocks to Energy Consumption Permanent or Temporary? New Evidence from a Panel SURADF Approach", Energy Economics, 30, 2314-2330.

Iledare, O.O. and W.O. Olatubi (2006), "Economic Effects of Petroleum Prices and Production in the Gulf of Mexico OCS on the US Gulf Coast Economy", M.M.S. U.S. Department of the Interior, Gulf of Mexico OCS Region, New Orleans, LA.

Im, K.S., M.H. Pesaran, and Y. Shin (2003), "Testing for Unit Roots in Heterogeneous Panels", Journal of Econometrics, 115, 53-74.

Im, K.S., M.H. Pesaran, and M. Tieslau (2005), "Panel LM Unit Root Tests with Level Shifts", Oxford Bulletin of Economics and Statistics, 67, 393-419.

Johansen, S. (2008), "A Representation Theory for a Class of Vector Autoregressive Models for Fractional Processes”, Econometric Theory, 24, 651-676.

Kang, S.H., S.M. Kang, and S.M. Yoon (2009), "Forecasting Volatility of Crude Oil Markets", Energy Economics, 31,119-125.

Karbassi, A.R., M.A. Abdul, and E.M. Abdollahzadegh (2007), "Sustainability of Energy Production and Use in Iran", Energy Policy, 35, 5171-5180.

Kaufmann, R.K., A. Bradford, L.H. Belanger, J.P. McLaughlin, and Y. Miki (2008), "Determinants of OPEC Production: Implications for OPEC Behaviour", Energy Economics, 30, 333-351.

Kaufmann, R.K. and C.J. Cleveland (2001), "Oil Production in the Lower 48 States: Economic, Geological, and Institutional Determinants", Energy Journal, 22, 27-49. 
Kwiatkowski, D., P. C. B. Phillips, P. Schmidt, and Y. Shin (1992), "Testing the Null Hypothesis of Stationarity against the Alternative of a Unit Root", Journal of Econometrics, 54, 159-178.

Lean, H.H. and R. Smyth (2009), "Long Memory in US Disaggregated Petroleum Consumption: Evidence from Univariate and Multivariate LM Tests for Fractional Integration", Energy Policy, 37, 3205-3211.

Lee, C.C. and C.P. Chang (2005), "Structural Breaks, Energy Consumption, and Economic Growth Revisited: Evidence from Taiwan", Energy Economics, 27, 857-872.

Lee, D., and P. Schmidt (1996). "On the Power of the KPSS Test of Stationarity against Fractionally Integrated Alternatives”. Journal of Econometrics, 73, 285-302.

Levin, A., C.F. Lin, C.S.J. Chu (2002), "Unit Root Tests in Panel Data: Asymptotic and Finite-Sample Properties", Journal of Econometrics, 108, 1-24.

Lien, D. and T.H. Root (1999), "Convergence to the Long-run Equilibrium: The Case of Natural Gas Markets", Energy Economics, 21, 95-110.

Maddala, G.S. and S. Wu (1999), "A Comparative Study of Unit Roots with Panel Data and a New Simple Test", Oxford Bulletin of Economics and Statistics, 61, 631-651.

Maslyuk, S. and R. Smyth (2009), "Non-linear Unit Root Properties of Crude Oil Production", Energy Economics, 31, 109-118.

Mishra, V., S. Sharma, and R. Smyth (2009), "Are Fluctuations in Energy Consumption Per Capita Stationary? Evidence from a Panel of Pacific Island Countries", Energy Policy, 37, 2318-2326.

Mohn, K. and P. Osmundsen (2008), "Exploration Economics in a Regulated Petroleum Province: The Case of the Norwegian Continental Shelf", Energy Economics, 30, 303-320.

Narayan, P.K. and R. Smyth (2007), "Are Shocks to Energy Consumption Permanent or Temporary? Evidence from 182 Countries", Energy Policy, 35, 333-341.

Narayan, P. K. and R. Smyth (2008), "Energy Consumption and Real GDP in G7 Countries: New Evidence from Panel Cointegration with Structural Breaks", Energy Economics, 30, 2331-2341.

Narayan, P.K., S. Narayan, and R. Smyth (2008), "Are Oil Shocks Permanent or Temporary? Panel Data Evidence from Crude Oil and NGL Production in 60 Countries", Energy Economics, 30, 919-936.

Nelson, C.R. and C.I. Plosser (1982), "Trends and Random Walks in Macroeconomic Time Series”, Journal of Monetary Economics, 10, 139-162.

Ozturk, I. (2010), "A Literature Survey on Energy-Growth Nexus", Energy Policy, 38, 340-349.

Payne, J.E. (2010a), "Survey of the International Evidence on the Causal Relationship between Energy Consumption and Growth", Journal of Economic Studies, 37, 53-95. 
Payne, J.E. (2010b), "A Survey of the Electricity Consumption-Growth Literature", Applied Energy, 87, 723-731.

Phillips, P.C.B. and P. Perron (1988), “Testing for a Unit Root in Time Series Regression”, Biometrika, 75, 335-346.

Ramazani, R.K. (1988), The Gulf Cooperation Council: Record and Analysis, The University Press of Virginia: Charlottesville, VA.

Rao, B.B. and G. Rao (2009), "Structural Breaks and Energy Efficiency in Fiji", Energy Policy, 37, 39593966.

Robinson, P.M. (1994), "Efficient Tests of Nonstationary Hypotheses", Journal of the American Statistical Association, 89, 1420-1437.

Robinson, P.M. and J. Hualde (2003), "Cointegration in Fractional Systems with Unknown Integration Orders", Econometrica, 71, 1727-1766.

Schwarz, G. (1978), "Estimating the Dimension of a Model”, Annals of Statistics, 6, 461-464.

Smith, A.D. (2005), "Level Shift and the Illusion of Long Memory in Economic Time Series", Journal of Business and Economic Statistics, 23, 321-335.

Smith, J.L. (2009), “World Oil: Market or Mayhem?”, Journal of Economic Perspectives, 23, 145-164.

Tsoskounoglou, M., G. Ayerides, and E. Tritopoulos (2008), "The End of Cheap Oil: Current Status and Prospects", Energy Policy, 36, 3797-3806.

Yao, Y.C. (1988), "Estimating the Number of Change Points via Schwarz' Criterion", Statistics and Probability Letters, 6, 181-189.

Yao, Y.C. and S.T. Au (1989), "Least Squares Estimation of a Step Function", Sankhya, Ser. A, 51, 370381. 